\title{
Lead Poisoning
}

\author{
ASSOCIATION WITH HEMOLYTIC ANEMIA, BASOPHILIC STIPPLING, \\ ERYTHROCYTE PYRIMIDINE 5'-NUCLEOTIDASE DEFICIENCY, AND \\ INTRAERYTHROCYTIC ACCUMULATION OF PYRIMIDINES
}

\author{
William N. Valentine, Donald E. Paglia, Kay Fink, and \\ GlenN MadoKoro
}

From the Departments of Medicine and Pathology, University of California, Center for the Health Sciences, Los Angeles, California 90024 and the

Wadsworth General Hospital, Veterans Administration Center, Los Angeles, California 90073

\begin{abstract}
A B S T R A C T Lead intoxication is accompanied by an acquired deficiency of erythrocyte pyrimidine-specific, 5 -nucleotidase. Genetically determined deficiency of this enzyme is associated with chronic hemolysis, marked basophilic stippling of erythrocytes on stained blood films, and unique intraerythrocytic accumulations of pyrimidine-containing nucleotides. The present report documents that lead-induced deficiency when sufficiently severe gives rise to findings similar to the hereditary disorder. Whereas pyrimidine-containing nucleotides are virtually absent in the erythrocytes of normal and reticulocyte-rich blood, $12 \%$ of erythrocyte nucleotides in the blood of a patient with lead intoxication contained cytidine. Nucleotidase activity was about $25 \%$ that in normal erythrocytes and $15 \%$ or less of that expected in comparable reticulocyte-rich blood. The distribution of nucleotidase activity in patient erythrocytes is unknown. and much more severe deficiency could have been present in subsets of the cell populations analyzed. The findings indicate that the hemolytic anemia and increased basophilic stippling characteristic of certain cases of lead intoxication may share a common etiology with essentially identical features of the genetically determined disorder.
\end{abstract}

\section{INTRODUCTION}

Hereditary hemolytic anemia occurs in association with a severe genetically determined deficiency of pyrimidine-

Received for publication 2 January 1976 and in revised form 17 May 1976. specific 5'-nucleotidase (E.C.3.1.3.5.) present in erythrocytes but not yet demonstrated in other tissues $(1,2)$. The syndrome is associated with a marked degree of basophilic stippling on the stained blood film and with large intraerythrocytic accumulations of nucleotides. About $80 \%$ of the latter are either cytidine or uridine, with cytidine predominating. Pyrimidine nucleotides, when detected at all, are present in only minute amounts in normal erythrocytes (3-11). Nucleotidase-deficient cells are unable to dephosphorylate, and thus render diffusible, the pyrimidine $5^{\prime}$-nucleoside monophosphates which result from degradation of ribosomal RNA by ribonucleases as the reticulocyte matures (1). The accumulated pyrimidine nucleotides are believed to retard RNA breakdown (1) with resulting aggregations of undegraded and partially degraded ribosomes giving rise to basophilic stippling as their morphologic counterpart. We have recently presented data indicating that the pyrimidine $5^{\prime}$-nucleotidase of normal erythrocytes is markedly inhibited in vitro by low concentrations of lead and certain other heavy metals, and that lead overburden in man in vivo is associated with substantial and sometimes very marked reductions in the erythrocyte nucleotidase activity (12). While the erythrocytes of 15 subjects with documented lead overburden exhibited nucleotidase activity ranging from 11 to $70 \%$ and averaging about $40 \%$ of normal, only one exhibited anemia, and this was mild. In none was basophilic stippling prominent on the stained blood film. In these subjects it was not possible to demonstrate significant accumulations of pyrimidine nucleotides within the erythrocytes. It was postulated, however, that the lead-induced nucleotidase deficiency, 
TABLE I

Hemotologic Findings before, during, and after Admission for Lead Intoxication

\begin{tabular}{|c|c|c|c|c|c|c|c|c|c|}
\hline Date & WBC & RBC & $\mathrm{Hb}$ & PCV & $\mathrm{MCV}$ & $\mathrm{MCH}$ & $\mathrm{MCHC}$ & Retics. & $\begin{array}{l}\text { Basophilic } \\
\text { stippling }\end{array}$ \\
\hline & $\times 10^{3} / \mu l$ & $\times 10^{6} / \mu l$ & $\mathrm{~g} / 100 \mathrm{ml}$ & $\%$ & $\mu^{3}$ & $\gamma \gamma$ & $\%$ & $\%$ & \\
\hline 9 March $1972^{*}$ & 16.4 & 5.18 & 16.0 & 46.8 & 90.0 & 31.0 & 34.0 & 一 & Normal \\
\hline 24 July $1975 \ddagger$ & 7.4 & 3.74 & 10.4 & 32.1 & 83.0 & 27.6 & 33.0 & - & +++ \\
\hline 20 November $1975 \S$ & 9.3 & 4.17 & 9.9 & 35.0 & 83.9 & 23.7 & 28.3 & $9.1-24$ & $++t+$ \\
\hline 30 January $1976 \|$ & 8.1 & 5.03 & 14.0 & 42.5 & 79.0 & 27.8 & 35.2 & 1.7 & + \\
\hline 11 March 1976\| & 7.6 & 5.08 & 14.2 & 41.0 & 81.0 & 27.8 & 34.8 & 0.8 & + \\
\hline 10 May $1976 \|$ & 8.6 & 5.23 & 15.5 & 45.0 & 86.0 & 29.6 & 34.4 & 2.1 & Normal \\
\hline
\end{tabular}

Basophilic stippling was judged on Wright's stained peripheral blood films.

Abbreviations: $\mathrm{MCH}$, mean corpuscular hemoglobin ; $\mathrm{MCHC}$, mean corpuscular hemoglobin concentration ; MCV, mean corpuscular volume; PCV, packed cell volume; RBC, erythrocytes; Retics., reticulocytes; WBC, leukocytes.

* Admitted for perforated appendix.

$\ddagger$ Removal of ganglion cyst from finger.

\$ Representative hemogram during admission for lead intoxication.

\| After last occupational exposure to lead which occurred about 11 November 1975.

if sufficiently severe, should lead to hemolytic anemia, increased basophilic stippling, and accumulations of pyrimidine nucleotides in erythrocytes in a manner analogous to that of the genetically determined deficiency. If such were the case, lead-induced nucleotidase deficiency would represent one mechanism leading to the hemolytic anemia and prominent basophilic stippling long recognized as characteristic features of certain cases of severe lead intoxication. The subject reported here had the requisite hematologic features essential for testing the hypothesis, and the following studies indicate that lead intoxication and the hereditary disorder have in common a hemolytic syndrome with very similar clinical, morphological, and biochemical characteristics.

\section{CASE REPORT}

Present history. The patient, a 26-yr-old MexicanAmerican spray painter, entered the hospital complaining of 2 days of sharp, more or less constant epigastric and back pain. On admission the latter had largely subsided, but epigastric pain persisted and was accompanied by anorexia, nausea, and vomiting. He denied aspirin ingestion, melena, hematemesis, ulcer disease, or prior abdominal pain. He had worked as a spray painter for $8 \mathrm{yr}$ and for his present employer 9 mo. He denied knowledge of lead being a component of the paints he had used during the last $3 \mathrm{yr}$. He was unaware of similar illness among co-workers or family members or of other potential exposures to lead-containing materials. He denied drinking or eating liquids or foods stored in glazed pottery.

Past history. Surgery had been performed for a perforated appendix in UCLA Hospital in March of 1972 with an uneventful recovery. A ganglion cyst on the left ring finger had been removed surgically 24 July 1975.

Physical examination. The positive findings consisted of mild tenderness localized to the epigastrium, poor dental hygiene with a gray-blue discoloration compatible with a so-called "lead line" on all of his gingiva, and orthostatic hypotension (blood pressure 135/90 supine to $85 / 45$ erect). Neurological examination was within normal limits.

Hematologic findings (Table I). The total and differential leukocyte count and blood platelets were normal. Moderately severe anemia with reticulocytosis ranging from 9.5 to $24 \%$, persisted during the week of hospitalization. The erythrocytes on the stained blood film exhibited anisocytosis, moderate to marked hypochromasia and polychromasia, and many erythrocytes were coarsely or finely stippled (Fig. 1). A rare nucleated erythrocyte was noted. The serum iron $(87 \mu \mathrm{g} / 100 \mathrm{ml})$ and total iron binding capacity $(278 \mu \mathrm{g} / 100 \mathrm{ml})$ were normal. Bone marrow aspiration revealed a mildly hypercellular marrow with erythroid predominance and abundant stainable iron.

$X$-ray studies. Upper gastrointestinal $\mathrm{X}$ rays showed a mild deformity of the duodenal bulb without ulceration and probable paralytic ileus without evidence of intestinal obstruction. A barium enema and sigmoidoscopy revealed no abnormality. An intravenous pyelogram was essentially normal.

Other laboratory studies. Other studies were unremarkable, including serum electrolytes, creatinine, glucose, calcium, amylase. albumin and total protein, a variety of liver function tests, and blood cortisone levels. The Coombs' antiglobulin test was negative.

Special studies for lead overburden (Table II). Blood and urine lead were markedly elevated as were 


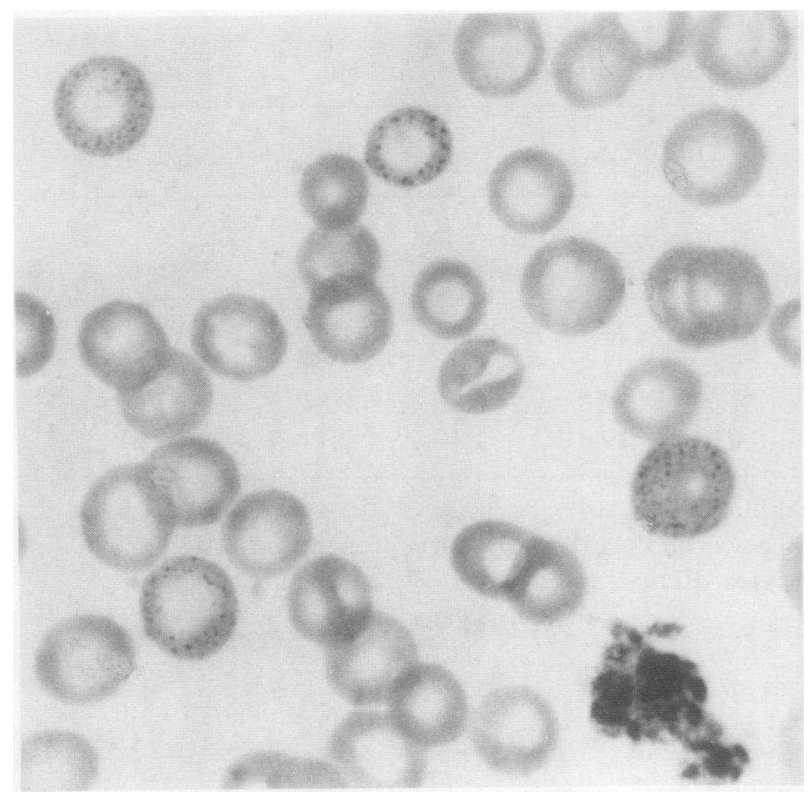

FIgURE 1 Photomicrograph. Wright's stained blood film. Note marked basophilic stippling. (magnification $\times 1,000$ ).

urinary delta-aminolevulinic acid (ALA), ${ }^{1}$ coproporphyrin, and uroporphyrin.

Hospital course. The abdominal pain subsided over a 3-day period, but the hematologic findings persisted. Orthostatic hypotension, secondary to the vomiting, anorexia, and consequent blood volume depletion, was rapidly corrected by the administration of intravenous saline. The patient was discharged after $1 \mathrm{wk}$ to be followed as an outpatient. The source of lead intoxication was subsequently traced to paint containing large amounts of lead and occupationally employed by the patient during the 9 mo before hospitalization.

Family studies. Both parents and a brother and a sister of the patient had normal hemograms. The blood lead determinations in both the father and mother were normal ( 36 and $26 \mu \mathrm{g} / 100 \mathrm{ml}$ of blood, respectively).

\section{METHODS}

Erythrocytes were separated from leukocytes and platelets by cotton filtration of saline-washed blood followed by multiple saline washes. Activities of glycolytic, hexose monophosphate shunt, and certain nonglycolytic enzymes were assayed as detailed in previous reports $(1,13-19)$. The activity of adenylate kinase was determined essentially as described by Haslam and Mills (20) and that of adenosine deaminase was measured as described by Beutler (21). Erythrocyte-reduced glutathione was measured by the method of Beutler et al. (22). Glycolytic intermediates, with the exception of 2,3-diphosphoglycerate, were quantitated by the method of Minakami et al. (3). 2,3-Diphosphoglycerate was assayed by a slight modification of the

${ }^{1}$ Abbreviations used in this paper: ALA, delta-aminolevulinic acid; $\mathrm{P}_{\mathbf{1}}$, inorganic phosphorus. method of Krimsky (23). Hemolysates prepared by freezing and thawing three times were dialyzed essentially free of endogenous phosphates and then assayed for pyrimidine $5^{\prime}$-nucleotidase activity as previously described $(1,2)$. The assays were performed at $37^{\circ} \mathrm{C}$ with $2.2 \mathrm{mM} \mathrm{UMP}$ or $\mathrm{CMP}$ as substrate at $\mathrm{pH}$ 7.4. Assays were made with and without addition of $0.010 \mathrm{ml}$ of $0.1 \mathrm{M}$ dithiothreitol (Cleland's reagent, obtained from Calbiochem, San Diego, Calif.), a reducing agent affording protection to sensitive enzyme sulfhydryl groups. After deproteinization with trichoroacetic acid, inorganic phosphorus $\left(\mathrm{P}_{1}\right)$ liberated by the nucleotidase was assayed, and activity was expressed as micromoles of $\mathrm{P}_{1}$ evolved per hour per gram of hemoglobin. The ultraviolet absorption spectra were determined at $\mathrm{pH} 2$ and 12 on extracts of washed erythrocytes as previously described (1). All assays for blood and urinary lead, ALA, and copro- and uroporphyrins were obtained through the UCLA Hospital Clinical Laboratory. Specimens submitted for chromatographic analysis were prepared as follows. Erythrocyte suspensions in saline containing known numbers of cells and freed of leukocytes and platelets were frozen and thawed, diluted with measured amounts of water, and deproteinized in a boiling water bath for $12-15 \mathrm{~min}$. After centrifugation and filtration, the resultant solution was brought to $\mathrm{pH} 7.8$ with the minimal required amount of 1.0 M Tris- $\mathrm{HCl}$ buffer, $\mathrm{pH}$ 8.0. To convert the mixture of nucleotides to nucleosides and thus simplify chromatography, the following was added to $4-5 \mathrm{ml}$ of filtrate before incubation at $37^{\circ} \mathrm{C}$ for $3-4 \mathrm{~h}: 6 \mathrm{U}$ of $5^{\prime}$-nucleotidase, $6 \mathrm{U}$ of nucleotide pyrophosphatase, and $6 \mathrm{U}$ of Escherichia coli alkaline phosphatase (all from Sigma Chemical Co., St. Louis, Mo.). This had been determined empirically to give preparations of nucleosides satisfactory for subsequent chromatography. After incubation the filtrates were again placed in a boiling water bath for $15 \mathrm{~min}$, and denatured enzyme protein was removed by centrifugation.

The procedures for separation of the nucleosides by two dimensional paper chromatography and the subsequent estimation of their concentrations from ultraviolet absorbance spectrophotometric data have been described previously (1, 24. 25).

TABLE II

Findings Relative to Lead Overburden

\begin{tabular}{|c|c|c|c|}
\hline Test* & $\mathrm{Pat}$ & & Normal values \\
\hline Blood lead & $\begin{array}{l}\mu \mathrm{g} / 100 \mathrm{ml} \\
\quad \text { blood }\end{array}$ & $\begin{array}{c}\mu \mathrm{g} / 100 \mathrm{ml} \\
\text { packed } \\
R B C\end{array}$ & \\
\hline Initial & 100 & 285 & $\begin{array}{l}\text { Less than } 40 \mu \mathrm{g} / \\
100 \mathrm{ml} \text { blood }\end{array}$ \\
\hline 30 January 1976 & 69 & 162 & \\
\hline 11 March 1976 & 51 & 124 & \\
\hline 19 April 1976 & 54 & 129 & \\
\hline Urine lead $(\mu g / 2+h)$ & 403 & & Less than 100 \\
\hline $\begin{array}{l}\text { Urine } \delta \text {-aminolevulinic } \\
\text { acid }(m g / 2+h)\end{array}$ & 99 & & $1.7-7.0$ \\
\hline $\begin{array}{l}\text { Urine coproporphyrin }+ \\
(\mu g / 2+h)\end{array}$ & $\begin{array}{l}1,186 \\
2,570\end{array}$ & & $34-234$ \\
\hline $\begin{array}{l}\text { Urine uroporphyrin } \\
(\mu \mathrm{g} / 24 \mathrm{~h})\end{array}$ & 553 & & $14-57$ \\
\hline
\end{tabular}

* All determinations were made during initial week of hospitalization (8-15 Nov 1975) with exception of serial determinations of blood lead made at various intervals after last occupational exposure to lead (approximately 1 November 1975).

$\ddagger$ Two separate determinations. 


\section{RESULTS}

Clinical and hematologic. After removal from occupational exposure to lead the patient rapidly became asymptomatic. As indicated in Table I and Fig. 1, lead toxicity initially was associated with hemolytic anemia, reticulocytosis ranging from 9 to 24\%, and striking basophilic stippling evident on the Wright's stained blood film. In contrast, at the time of hospitalization for a perforated appendix in 1972, the hemogram had been entirely normal except for leukocytosis. However, a hemogram obtained on 24 July 1975 in conjunction with a minor surgical procedure and inserted in the patient's record only after his discharge indicated that both anemia and prominent basophilic stippling were present on that date (Table I). This was about 6 mo after the beginning of employment during which exposure to lead-containing paint occurred. Within approximately 3 mo after the November 1975 hospitalization for lead intoxication, the hemogram had returned essentially to normal as had the percentage of reticulocytes. Moreover, the basophilic stippling and hypochromia noted initially had virtually disappeared. In conjunction with this, the mean corpuscular hemoglobin and mean corpuscular hemoglobin concentration also normalized. These findings remained constant during subsequent studies.

Studies on lead overburden. The data presented in Table II document lead overburden in the patient as evidenced by the elevated levels of blood and urinary lead and high levels of urinary ALA and coproporphyrin. Although blood lead levels are customarily reported in terms of micrograms per $100 \mathrm{ml}$ of whole blood, Table II also expresses them per $100 \mathrm{ml}$ of packed erythrocytes. Blood lead is confined virtually entirely to the erythrocyte, and almost none is found in plasma (26). The degree of lead overburden, therefore, is more realistically appreciated when expressed in terms of erythrocyte numbers or volume. Failure to correct for differing erythrocyte numbers and volume in comparisons between the blood of nonanemic and substantially anemic subjects leads to erroneous evaluation of the lead burden actually present in the erythrocyte as a body tissue. Table II indicates that 5-6 mo after the last occupational exposure to leaded paint, the blood lead had fallen by about one-half when expressed per $100 \mathrm{ml}$ of blood and by about two-thirds when expressed per $100 \mathrm{ml}$ of packed erythrocytes.

Glycolytic intermediates and enzymes other than nucleotidase. The following erythrocyte enzyme activities were measured at the time of hospitalization and were either normal or compatible with a young mean cell age in the assayed population: hexokinase, glucosephosphate isomerase, phosphofructokinase, fructosediphosphate aldolase, triosephosphate isomerase, glyceraldehyde-3-phosphate dehydrogenase, phosphoglycerate kinase, lactate
TABLE III

Pyrimidine 5'-Nucleotidase Data

\begin{tabular}{clcc}
\hline & & \multicolumn{2}{c}{ Nucleotidase activity* } \\
\cline { 3 - 4 } & \multicolumn{1}{c}{ Date } & UMP & CMP \\
\hline Patient (Retics. 9-11\%) & 12 November 1975 & 2.1 & 1.6 \\
(Retics. 1.7\%) & 30 January 1976 & 2.5 & 1.6 \\
(Retics. 0.8\%) & 11 March 1976 & 2.1 & 1.7 \\
(Retics. 2.6\%) & 19 April 1976 & 5.1 & 4.3 \\
(Retics. 2.1\%) & 10 May 1976 & 5.4 & 4.6 \\
Normal (Mean) & & 8.0 & 7.0 \\
High retics. (5-10\%) & & & \\
Controls (Mean) & & 14.0 & 9.7 \\
\hline
\end{tabular}

* Expressed as micromoles $P_{i}$ liberated per hour per gram hemoglobin at $37^{\circ} \mathrm{C}$. Values for patient on 12 November 1975 were obtained during hospitalization for lead intoxication. For appropriate comparison of the data of 12 November 1975 , the higher than normal nucleotidase activity expected in reticulocyte-rich blood is also given. In subsequent studies the patient's hemogram had normalized and reticulocytosis was essentially absent. (See Table I).

dehydrogenase, adenylate kinase, glucose-6-phosphate dehydrogenase, phosphogluconate dehydrogenase, glutathione reductase, glutathione peroxidase, ribosephosphate pyrophosphokinase, adenine phosphoribosyltransferase, nucleosidemonophosphate kinase, malic dehydrogenase, adenosine deaminase, and glutamic oxalacetic transaminase. Erythrocyte GSH content was normal. All glycolytic intermediates between glucose and lactate were normal in concentration with the exception of 2,3-diphosphoglycerate which was reduced to $2.78 \mu \mathrm{mol} /$ $10^{10}$ erythrocytes. (Normal control mean value $=3.01$; reticulocyte-rich $4-16 \%$, control mean $=4.32$ ). Similar enzyme studies were performed on the erythrocytes of the parents of the patient and all activities were normal.

Nucleotidase activity. During the initial acute hemolytic syndrome, nucleotidase activity in patient erythrocytes was about $25 \%$ of the normal mean and $15 \%$ or less of that expected in comparably reticulocyte-rich blood (Table III). The latter estimate is conservative since the patient's reticulocyte count at the time of the studies was substantially higher than the mean of subjects with reticulocytosis cited for comparison in Table III. Nucleotidase activity is increased markedly and characteristically in reticulocyte-rich, young erythrocyte populations (1), and appropriate comparisons are possible only in the context of this fact. In absolute terms, erythrocyte nucleotidase activity changed little in the early months after removal from lead exposure; when appropriately viewed in terms of the much younger mean cell age during the period of acute hemolysis as compared to that pertaining after normalization of the hemogram, improvement in the direction of normal occurred. By 10 May 1976 nucleotidase activity had increased to $67 \%$ of the normal mean, now a fitting comparison in view of the normality of the patient's hemogram over the previous 3 mo. Nucleotidase activities in 
TABLE IV

Comparison of Isolated* and Authentic Cytidine

\begin{tabular}{|c|c|c|c|c|c|}
\hline & \multicolumn{2}{|c|}{ pH 2} & \multicolumn{2}{|c|}{$\mathrm{pH} 12$} & \multirow{2}{*}{$\frac{A_{\max }, p H 2}{A_{\max }, p H 12}$} \\
\hline & Maximum & Minimum & Maximum & Minimum & \\
\hline & $n m$ & $n m$ & $n m$ & $n m$ & \\
\hline Cytidine from $\mathrm{RBC}$ extracts & 277 & 242 & 267 & 252 & 1.34 \\
\hline Authentic cytidine & 278 & 240 & 269 & 250 & 1.35 \\
\hline
\end{tabular}

* By elution after chromatography of deproteinized erythrocyte extracts in which nucleotides had been converted to nucleosides.

the erythrocytes of the father, mother, and a brother and sister of the patient were all well within $1 \mathrm{SD}$ of the normal mean; with UMP as the substrate, activities expressed as in Table III were 6.7, 7.1, 9.5, and 6.8 enzyme units, respectively.

Spectral and chromatographic data. Ultraviolet absorption analyses repeatedly performed on several separate deproteinized hemolysates uniformly revealed a small shift of maximal absorption toward higher wavelengths as compared with data obtained on normal and reticulocyte-rich blood in other conditions. The reason for this aberration was apparent after composition of the ultraviolet-absorbing components of the extracts was ascertained by chromatographic analyses.

At the time of the November 1975 hospitalization. the pyrimidine nucleoside, cytidine, was identified in deproteinized and enzymatically dephosphorylated extracts prepared from the patient's erythrocytes. The spectral curves for the chromatographically isolated nucleoside were in close agreement with those of authentic cytidine (Table IV). The minor differences observed may be attributed to the background absorbance contributed by the filter paper. Four separate chromatographic analyses were made for the cytidine content of the extracts, and the analyses agreed within $5 \%$. Summation of the $A$ son recovered in the eluates of the chromatographic spots closely approximated that originally applied to the filter paper, indicating that no significant losses occurred during chromatography and subsequent elution procedures. Cytidine comprised $12 \%$ of the total nucleosides present, with adenosine and its deaminated derivative, inosine, accounting for the remainder. If uridine was present, it was in too low a concentration to be characterized by the methodology employed.

Extracts prepared on 30 January 1976, 3 mo after the last occupational exposure to lead, were subjected to identical chromatographic analyses. In contrast, no cytidine or uridine was now detectable, and as with erythrocytes from normal controls or from patients with reticulocytosis the eluted purines accounted essentially quantitatively for the $A_{980}$ applied to the chromatogram. Similar chromatographic studies performed on extracts of erythrocytes from both mother and father of the patient revealed only adenine-containing purines. No pyrimidines were detectable.

\section{DISCUSSION}

The most definitive feature of the hemolytic syndrome resulting from genetically determined nucleotidase deficiency is the accumulation of large amounts of intraerythrocyte pyrimidine nucleotides, an inevitable consequence of deficiency of the enzyme responsible for their dephosphorylation and elimination from the cell. Basophilic stippling has been shown by electron microscopy to represent aggregations of undegraded or partially degraded ribosomes (27). Its prominence in nucleotidase deficiency presumably reflects retardation of RNA ribosomal degradation secondary to inability to eliminate the pyrimidine nucleotide products resulting from the action of ribonucleases. The precise mechanism of hemolysis is not well defined and is. presumably, complex. However, pyrimidine nucleotides are capable of binding to the active sites of crucial glycolytic enzymes such as pyruvate kinase, hexokinase, and phosphoglycerate kinase where they compete with the far more efficient and preferred adenine-containing cofactors (1, 2). Thus ample opportunity exists through these and. quite possibly, through other unknown mechanisms for disruption of the delicate glycolytic machinery upon which the erythrocyte is dependent for survival.

Erythrocyte nucleotidase has been shown to be inhibited by low concentrations of lead in vitro (12). The patient reported here represents the 16th consecutive subject with documented lead intoxication and demonstrably low activity of erythrocyte nucleotidase studied in our laboratory. However, in the adult, even symptomatic lead overburden often is not associated with either hemolytic anemia or prominent basophilic stippling $(26,28)$, and the latter were absent in our previously reported cases. The subject of the present report provided the opportunity to determine if lead-induced nucleotidase deficiency could duplicate the major features of the hereditary syndrome, including, most crucially, intraerythrocytic accumulations of pyrimidine 
nucleotides. While the latter did not accumulate quantitatively to the same degree as in the hereditary disorder, the demonstration that $12 \%$ of erythrocyte nucleotides contained cytidine is unique, and accumulations of pyrimidine-containing nucleotides of this or greater degree have thus far only been observed in genetically determined and lead-induced nucleotidase deficiency (1-12).

In the present case, the severe hemolytic syndrome, the basophilic stippling, and the intracellular pyrimidines all rapidly disappeared after removal of the patient from occupational exposure to lead. This in conjunction with the entirely normal hemogram known to be present 3 $\mathrm{yr}$ before the present investigation rendered it certain that the hereditary syndrome was not responsible for the findings observed. However, the very low nucleotidase activity initially present, while consistent with previous observations in subjects with lead overburden (12), precluded certain knowledge of the status of nucleotidase activity prior to exposure to lead. It could not be categorically stated that pre-existing partial deficiency on a genetic basis might not have predisposed to the development of overt deficiency in the presence of exposure to lead. It appears unlikely that such is the case. Erythrocyte nucleotidase activity is entirely normal in both parents and two siblings of the patient. The patient's own erythrocyte nucleotidase activity has now risen to about two-thirds that of the normal mean. Moreover, while partial nucleotidase deficiency theoretically might facilitate the ability of lead to duplicate the features of the genetically determined syndrome, this would not obviate the fact that lead intoxication, if sufficiently severe, clearly can mimic the hereditary lesion in all essential respects.

We attribute the slow recovery of nucleotidase activity after removal of lead from the patient's environment to several causes. Blood lead is dependent upon the flux and constant redistribution of lead present in soft tissues and bone. Since blood and erythrocyte lead are virtually synonymous (26), the most lead-sensitive proteins of the erythrocyte will continue to be affected for as long as elevated blood lead levels persist in a given case. Continuing low nucleotidase activity is also favored by the fact that the enzyme functions only over a short critical period when pyrimidine products of RNA degradation must be eliminated from the cell. Even in the presence of substantial deficiency, if these products are eliminated before irreversible impairment of cell survival intervenes, the deficiency imposes no further handicap. The enzyme is without substrate or further function. In the absence of other reasons for shortened survival. its already low activity persists and diminishes further as the erythrocyte ages. This persisting deficiency is reflected in assay values until final removal of the erythrocyte from the circulation but is of no further moment to cellular function. Also all erythrocyte enzyme determinations measure a mean activity and fail to reflect its distribution among the population assayed. In the case reported here, the initially observed low activity may have derived from a limited subset of the cell population, other members of which may actually have been even more severely deficient. The association of hemolysis, basophilic stippling, and accumulations of pyrimidine nucleotides thus far demonstrated in no other conditions strongly suggests that the lead-induced and genetically induced syndromes share the severe deficiency of nucleotidase activity as a common etiology.

This, of course, does not imply that other hematologic abnormalities which may accompany lead overburden are on a similar basis. Lead affects metabolism at many points, and sideroblastic anemia, disturbed synthesis of hemoglobin, and disordered membrane function have been documented as other end results of the multiple actions of lead $(26,28-37)$. Indeed, a heavy metal capable of reacting with the ubiquitously distributed sulfhydryl groups which characterize so many crucial enzymes could hardly fail to produce metabolic aberrations at a multiplicity of loci.

In the erythrocytes of this subject GSH was not increased and ribosephosphate pyrophosphokinase activity was not reduced. These epiphenomena though of unknown etiology, do accompany the hereditary nucleotidase deficiency (1). Conceivably their absence in this subject with lead poisoning is related to the relatively lower concentration of erythrocyte pyrimidine nucleotides. While cytidine-containing nucleotides were predominant in the hereditary deficiency, uridine nucleotides were present to a lesser degree. In the present case, only cytidine-containing nucleotides were detected definitively, but this may reflect merely the relatively greater difficulty of isolating uridine if present as a minor component in the much lower concentration of total pyrimidine nucleotides characterizing this lead-induced as compared to the genetically induced disorder. It is also possible that the proportions of cytidine and uridine are for unknown reasons not identical in the hereditary as compared to lead-induced deficiencies.

\section{ACKNOWLEDGMENTS}

The authors gratefully acknowledge the technical assistance of Ms. M. Nakatami and S. Stribling, Mr. J. Brown, A. Eldakar, E. Guereque, and P. Morris. We also express our gratitude to Dr. Susan Harris, Albert Einstein University School of Medicine, Bronx, N. Y. and to Dr. Thomas W. Sheehy, University of Alabama School of Medicine, Birmingham, Ala. for their efforts to assist us to obtain blood specimens from appropriate cases of lead overburden.

This work was supported by a research grant from the National Institutes of Health U. S. Public Health Service HL 12944 and by U. S. Public Health Service General Research Support grant 5S01 RRP5354-14. 


\section{REFERENCES}

1. Valentine, W. N., K. Fink, D. E. Paglia, S. R. Harris, and W. S. Adams. 1974. Hereditary hemolytic anemia with human erythrocyte pyrimidine $5^{2}$-nucleotidase deficiency. J. Clin. Inv'est. 54: 866-879.

2. Paglia, D. E., and W. N. Valentine. 1975. Characteristics of a pyrimidine-specific 5'-nucleotidase in human erythrocytes. J. Biol. Chem. 250: 7973-7979.

3. Minakami, S., C. Suzuki, T. Saito, and H. Yoshikawa. 1965. Studies on erythrocyte glycolysis. I. Determination of the glycolytic intermediates in human erythrocytes. J. Biochem. (Tokyo). 58: 543-550.

4. Bartlett, G. R. 1959. Human red cell glycolytic intermediates. J. Biol. Chem. 234: 449-458.

5. Bishop, C. 1961. Changes in the nucleotides of stored or incubated human blood. Transfusion (Phila.). 1: 349-354.

6. Bishop, C., D. M. Rankine, and J. H. Talbott. 1959. The nucleotides in normal human blood. J. Biol. Chcm. 234: 1233-1237.

7. De Luca, C., J. H. Stevenson, Jr., and E. Kaplan. 1962. Simultaneous multiple-column chromatography: its application to the separation of the adenine nucleotides of human erythrocytes. Anal. Biochem. 4: 39-45.

8. Mandel, P., P. Chambon, H. Karon, I. Kulic, and M. Serter. 1962. Nucleótides libres des globules rouges et des réticulocytes. Folia Hacmatol. (Lcipz.). 78: 525543 .

9. Mills, G. C., and L. B. Summers. 1959. The metabolism of nucleotides and other phosphate esters in erythrocytes during in aitro incubation at $37^{\circ}$. Arch. Biochem. Biophy's. 84 : 7-14.

10. Scholar, E. M., P. R. Brown, R. E. Parks, Jr., and P. Calabresi. 1973. Nucleotide profiles of the formed elements of human blood determined by high-pressure liquid chromatography. Blood. 41: 927-936.

11. Yoshikawa, H., M. Nakano, K. Miyamoto, and M. Tatibana. 1960. Phosphorus metabolism in human erythrocyte. II. Separation of acid-soluble phosphorus compounds incorporating $\mathrm{P}^{32}$ by column chromatography with ion exchange resin. J. Biochem (Tokyo). 47: 635648.

12. Paglia, D. E., W. N. Valentine, and J. G. Dahlgren. 1975. Effects of low-level lead exposure on pyrimidine 5 '-nucleotidase and other erythrocyte enzymes. Possible role of pyrimidine $5^{\prime}$-nucleotidase in the pathogenesis of lead-induced anemia. J. Clin. Inc'est. 56: 1164-1169.

13. Baughan, M. A., W. N. Valentine, D. E. Paglia, P. O Ways, E. R. Simons, and Q. B. DeMarsh. 1968. Hereditary hemolytic anemia associated with glucosephosphate isomerase (GPI) deficiency-a new enzyme defect of human erythrocytes. Blood. 32: 236-249.

14. Koutras, G. A., M. Hattori, A. S. Schneider, F. G. Ebaugh, Jr., and W. N. Valentine. 1964. Studies on chromated erythrocytes. Effect of sodium chromate on erythrocyte glutathione reductase. J. Clin. In'est. 43: 323331.

15. Paglia, D. E., and W. N. Valentine. 1967. Studies on the quantitative and qualitative characterization of erythrocyte glutathione peroxidase. J. Lab. Clin. Med. 70 : 158-169.

16. Schneider, A. S., W. N. Valentine, M. Hattori, and H. L. Heins, Jr. 1965. Hereditary hemolytic anemia with triosephosphate isomerase deficiency. N. Enyl. J. $M c d$. 272: 229-235.

17. Valentine, W. N., F. A. Oski, D. E. Paglia, M. A
Baughan, A. S. Schneider, and J. L. Naiman. 1967. Hereditary hemolytic anemia with hexokinase deficiency. Role of hexokinase in erythrocyte aging. N. Engl. J. Mcd. 276: 1-11.

18. Valentine, W. N., D. E. Paglia, R. C. Neerhout, and P. N. Konrad. 1970. Erythrocyte glyoxalase II deficiency with coincidental hereditary elliptocytosis. Blood. 36: 797-808.

19. Valentine, W. N., and K. K. Kürschner. 1972. Studies on human erythrocyte nucleotide metabolism. I. Nonisotopic methodologies. Blood. 39: 666-673.

20. Haslam, R. J., and D. C. B. Mills. 1967. The adenylate kinase of human plasma, erythrocytes and platelets in relation to the degradation of adenosine diphosphate in plasma. Biochem. J. 103: 773-784.

21. Beutler, E. 1975. Adenosine deaminase (AD). In Red Cell Metabolism: A Manual of Biochemical Methods. E. Beutler, editor. Grune and Stratton, Inc., New York. 2nd edition. 85-86.

22. Beutler, E., O. Duron, and B. M. Kelly. 1963. Improved method for the determination of blood glutathione. $J$ Lab. Clin. Med. 61: 882-888.

23. Krimsky, I. 1963. D-2,3-diphosphoglycerate. In Methods of Enzymatic Analysis, H. U. Bergmeyer, editor. Academic Press Inc., New York. 238-240.

24. Fink, K., and W. S. Adams. 1966. Paper chromatographic data for purines, pyrimidines and derivatives in a variety of solvents. J. Chromatogr. 22: 118-129.

25. Fink, K., R. E. Cline, and R. M. Fink. 1963. Paper chromatography of several classes of compounds: Correlated $\mathrm{R}_{\mathrm{f}}$ values in a variety of solvent systems. Anal Chcm. 35: 389-398.

26. Albahary, C. 1972. Lead and hemopoiesis. The mechanism and consequences of the erythropathy of occupational lead poisoning. Am. J. Med. 52: 367-378.

27. Jansen, W. N., G. D. Moreno, and M. C. Bessis. 1965 An electron microscopic description of basophilic stippling in red cells. Blood. 25: 933-943.

28. Waldron, H. A. 1966. The anaemia of lead poisoning. A review. Br. J. Ind. Mcd. 23: 83-100.

29. White, J. M., and D. R. Harvey. 1972. Defective synthesis of $\alpha$ and $\beta$ globin chains in lead poisoning. Naturc (Lond.). 236: 71-73.

30. Goldberg, A. 1968. Lead poisoning as a disorder of heme synthesis. Simin. Hcmatol. 5: 424-433.

31. Goldberg, A. 1972. Lead poisoning and haem biosynthesis. Br. J. Hacmatol. 23: 521-524.

32. Vincent, P. C. 1958. The effects of heary metal ions on the human erythrocyte. II. The effects of lead and mercury. Aust. J. Exp. Biol. Mid. Sci. 36: 589-601.

33. Hasan, J., V. Vihko, and S. Hernberg. 1967. Deficient red cell membrane $\left[\mathrm{Na}^{+}+\mathrm{K}^{+}\right]-$ATPase in lead poisoning. Arch. Enitiron. Hcalth. 14: 313-318.

34. Secchi, G. C., L. Ambrosi, and A. Rezzonico. 1968 Ricerche sulla $\mathrm{Na}^{+}-\mathrm{K}^{+}$-ATPasi e sulla acetilcolinesterase delle membrane eritrocitarie nell' anemia saturnina. Mcd. Laz: 59: 593-598.

35. Angle, C. R., and M. S. McIntire. 1974. Red cell lead, whole blood lead, and red cell enzymes. Enciron. Health Pcrspect. 7: 133-137.

36. Rogers, L. E., N. D. Battles, E. W. Reimold, and P Sartain. 1971. Erythrocyte enzymes in experimental lead poisoning. Arch. Toxikol. 28: 202-207.

37. Bonsignore, D. 1966. L'attivita' ALA-deidratasica eritrocitaria quale test diagnostico nel saturnismo professionale Mcd. Lai' 57: 647-654. 